\title{
The "Ciel, miroir des cultures" exhibition: a three-year awareness campaign on the sky as a mirror of cultures
}

\author{
Olivier Las Vergnas ${ }^{1,2}$, Eric Piednoël ${ }^{2}$ and Gérard Gautier ${ }^{3,2}$ \\ ${ }^{1}$ Centre de recherches éducation et formation (CREF), \\ Université Paris Ouest Nanterre La Défense, \\ Bâtiment C, 200, avenue de la République, 92001 Nanterre Cedex, France \\ email: o.lasvergnas@cite-sciences.fr \\ ${ }^{2}$ Association Française d'Astronomie, \\ 17, rue Émile Deutsch de la Meurthe, 75014 Paris, France \\ email: eric.piednoel@afanet.fr \\ ${ }^{3}$ Institut National des Langues et Civilisations Orientales, \\ 2 rue de Lille, 75343 Paris, France \\ email: g.gautierk@online.fr
}

\begin{abstract}
The Ciel, miroir des cultures poster-exhibition was designed by the Association Française d'Astronomie and printed in 300 copies in 2005. Each copy is composed of 14 posters introducing the different ways human beings and societies have used the sky and the heavens in history. More than three hundred cultural events have now been using the exhibition in schools and community structures as public libraries and social centres, taking place mainly in lowincome urban or suburban neighbourhoods. This three-year work demonstrated the relevance of this kind of tools and events to pedagogical and social aims, specifically if the event is not limited to showing posters and also offers an opportunity for dialogue.
\end{abstract}

Keywords. awareness, ethnology, public understanding of science, exhibition

\section{Introduction}

The Association Française d'Astronomie (AFA, www.afanet.fr) is a national nonprofit organisation dedicated to promote interest and knowledge sharing in fields related to astronomy. AFA aims at giving the largest audience the desire and means to discover and share astronomy, including related sciences and technologies. On the one hand, AFA acts as a publishing company, printing monthly 100,000 copies of its magazine Ciel et espace† (Sky and Space) and on the other hand, functions as a national network setting up awareness campaigns and nationwide coordinated events. For instance, in cooperation with the network of its sister association Planète Science and the France 2 TV channel, AFA set up the first event Nuit des étoiles filantes (Shooting stars night) in 1991 and has been coordinating it each year since then $\ddagger$.

AFA publishes, among other tools, series of poster-exhibitions intended to support its member associations and partners to set up local astronomical events. Initiated in 1999 for the total solar eclipse, this practice was reiterated in 2000 and 2001 for the events Nuit des étoiles. AFA published each year a specific series of six posters linked to the topic selected for the Nuit des étoiles edition. Another exhibition, called Les 4 saisons du temps (Time's four seasons), was more ambitious: consisting of twelve $100 \times 70 \mathrm{~mm}$ posters, and

$\dagger$ counting over 22,000 subscribers.

$\ddagger$ see page 725 in this volume for a detailed account. 
published in 200 copies thanks to funding by Casden-BP, a teachers' cooperative bank, this exhibition was specifically conceived as a support for teacher training in multidisciplinary school projects. Is main topic, time and calendars, had been chosen precisely because it lends itself to numerous points of view, thus facilitating teacher team work in multi-disciplinary projects. The free distribution of this exhibition to all French teachers training institutes spurred the setting up of several astronomical events.

In another field of activity, AFA decided since 1996 to set up an experimental program to extend activities in astronomical awareness to low-income urban or suburban neighbourhoods rigged by social and unemployment problems. The residents of such neighbourhoods typically belong to diverse cultural origins, which often have during their history projected their respective beliefs onto the sky. On the other hand, our present standard scientific sky still uses Mesopotamian asterisms shapes and a large majority of stars' common names is from Arabic. Are those children of former migrants to France, often in search for their cultural roots, aware of that? What is the place of astronomy in the new artistic activities where those youngsters get involved? This operation, entitled Ciel des quartiers (CdQ) - a name which might be rendered in English as My neighbourhoodss sky- funded by Ministry of youth, involved astronomers, anthropologists, sociologists, educators, social workers, community members and even a theatre company. All these partners built together different supports for activities, then distributed together in one hundred copies by AFA as a CdQ Activities Kit. It included a roadmap for local activity leaders or coordinators, a multilingual astronomy lexicon (with entries in Arabic, Chinese, ancient Egyptian, ...), a short anthology of sky tales from diverse human cultures and a set of three large sky map posters. One of the maps was a reproduction of Philippe de la Hire's XVII century map, the two others being original creations from research carried out by one of the authors on the Chinese and Arabic traditions, a Chinese sky map from Qing dynasty epoch as commented by Chevalier de Guignes (De Guignes 1782), and an Arabic one inspired from Ulugh Beg's 15th century catalog (Knobel 1917).

CdQ activities were carried out from 1997 to 2000. The initial objective of CdQ was to open the network of astronomical leisure to a new kind of partners and new areas and audience as well. The operation was expected to generate among social workers involved with inter-cultural or inter-communities linking programmes interest in using astronomy and, along the way, to enlarge the general audience of astronomy. However, the evaluation of 1997-2000 CdQ campaigns produced the two following results:

- New kinds of stakeholders (social centres, public libraries, protection judiciaire de la jeunesse -judicial youth protection office- and charities), got rapidly interested to CdQ activities;

- Each of them needed a link with astronomical awareness specialists (local clubs, etc) to be able to manage their $\mathrm{CdQ}$ projects.

This meant that CdQ was relevant to attract new partners, but did not help enlarging the audience because it proved very difficult to start activities in locations far from local human astronomical resources. Symmetrically, few of the existing astronomy clubs felt themselves able to accompany efficiently such new types of events.

\section{CMC project and material}

In 2004, the authors decided to restart a new CdQ generation, this time using posters exhibitions, supposed to have a better awareness generation power: the hypothesis was that such ready to use, self-contained tools could be showed by any stakeholder, regardless of its proximity to a local astronomical club. In line with CdQ goals, this new poster exhibition would offer an anthropological introduction to the ways human beings deal 
with heavens. To match better the interest of the audience, the authors organized the exhibition differently from usual books or exhibitions: instead following different civilisations or ethno-geographic areas, CMC categorised the information according to invariant worldwide uses of the heavens, along two main lines: collective uses such a predict and dominate and individual uses as guess what future will be.
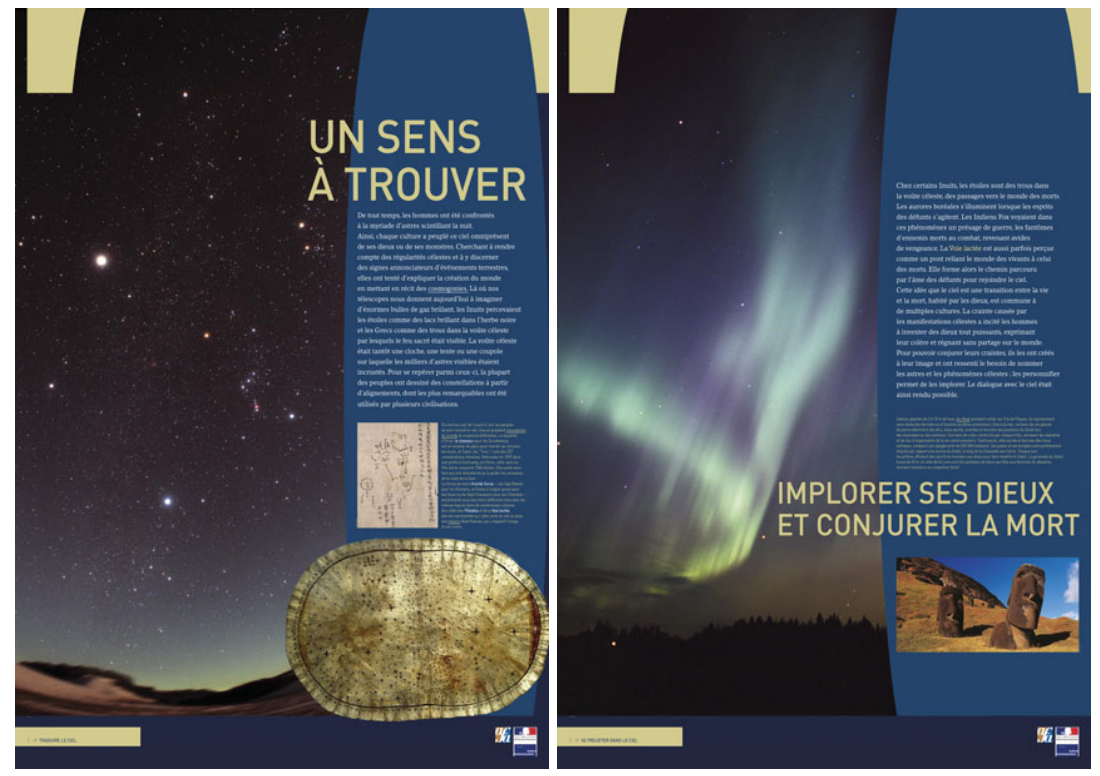

Figure 1. Two examples of CMC posters: Need for a meaning from the introductory part and Pray the gods and conjure death from the part on personal uses.

That is how AFA, with the support of the Ministry of Culture, published in July 2005 Ciel, Miroir des Cultures (CMC, which can be translated as Sky, mirror of human cultures. Figure 1 shows a facsimile of 2 among the 14 posters. As for the former 4 saisons du temps, the exhibition comes with several supplementary activities supports, e.g. pedagogical guidelines or papers extracted from AFA's Ciel et Espace magazine. A web resource centre offers around one hundred specific resources documenting all the aspects of the exhibition, including a heavens tales database inspired from local cultures from specific Indian, Native American, Arabic, Chinese and European areas (Las Vergnas et al. 2005).

\section{CMC distribution, uses and users}

The official distribution of CMC began at the end of 2005. As it had been designed to lend itself to creative uses as well as to a ready to use setting-up (you receive it, you hang it), the authors thought irrelevant to send along a standardised questionnaire. On the contrary, they invited each user to create his own evaluation scheme, as the only way to take in account the specificities of each target audience, context of presentation and pedagogical framework and partner. To elicit usage reports, they gave the whole exhibition for free if the user vouched to send back a detailed pedagogical report. The exhibition could also be bought for $55 €$.

Unfortunately, most of the users preferred this latter mode of acquisition. At the beginning of 2009, 265 copies had been distributed and used by several kinds of users (excluding direct AFA internal uses), which confirmed the power of this kind of tool 
for disseminating astronomical general content. Fig. 2 shows CMS users' institutional distribution but no relevant data is available about the total number of events using CMC: several users framed the posters or coated them with plastic to increase their life span and so show them in several locations. Some specialised resources centres even dedicated copies to be rented to sub-users. The spectrum of CMC organizers has then been larger that originally intended by the authors. It includes communities or educational centres installed in disadvantaged neighbourhoods as well as scientific research centres or libraries (e.g. the prestigious French Ecole Polytechnique and some universities). Finally, CMC appeared to be a relevant multipurpose door to the skies allowing a dialogue among people from different social categories or communities.

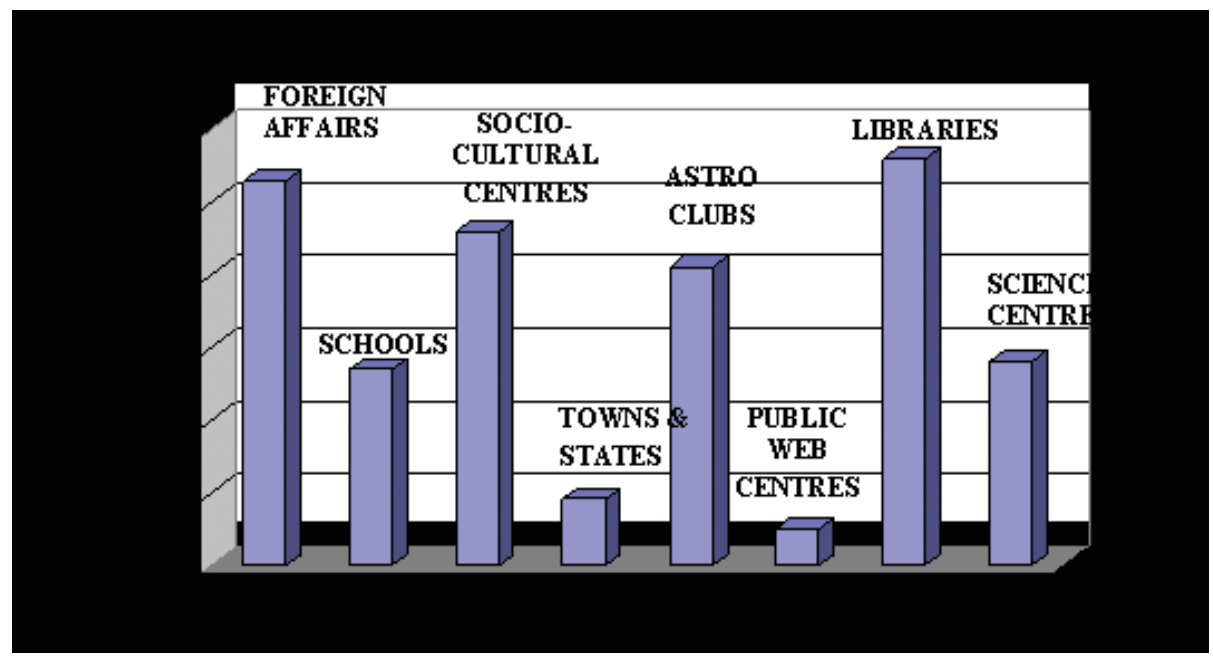

Figure 2. Number of distributed copies versus categories of organisers.

\subsection{Cumulated audience}

As the authors possess relevant quantitative data only for CMC operations directly organized by AFA, the total audience of the project can only be estimated a minima. As detailed further below, AFA has led in 2007 and 2008 two important regional CMC operations in Ile-de-France (i.e. Greater Paris area). Between May 2007 and February 2009, 47 events representing 59 weeks of animation reached 18,000 people. In these operations, the audience in each location averaged 400, including topical workshops and 250 exhibition visitors. From this value of 250 exhibition visitors per event and 300 copies distributed and used, we get a total audience for CMC of more than 75,000 people. However, in several cases, each copy may have spurred several other introductory events: e.g. in the southern France Toulouse region, where local partners received 2,900 people and 45 families. Another particularly successful operation was organised in Lourdes by young people from the Astroclub Lourdais with support and educative materials from AFA.

As some copies were shown as well in widely open places as the great exhibition hall of the Cité des sciences et de l'industrie de La Villette (French national science museum) that have received a number of visitors closer to 1,000 than 250 , the real value for CMC exhibition cumulated audience is probably nearer to 100,000 than the minimum given value of 75,000 . 


\subsection{Case study}

Greater Paris IdF CMC in 2007: From January to March 2007 in 6 suburban cities of Seine-Saint-Denis department (Greater Paris North-Eastern low income area), and from October to December in seventeen other Ile-de-France cities, AFA set up 25 events under the common name Ciel miroir des cultures, miroir des quartiers ( Sky as a mirror of human culture and of my neighbourhood). Funded by Ile-de-France area authority, this operation involved 24 different local animators or demonstrators and reached 2,622 youngsters, through 134 half-day workshops, 13 lectures and 3 training sessions. The whole audience of the exhibition was approximately 9,000 .
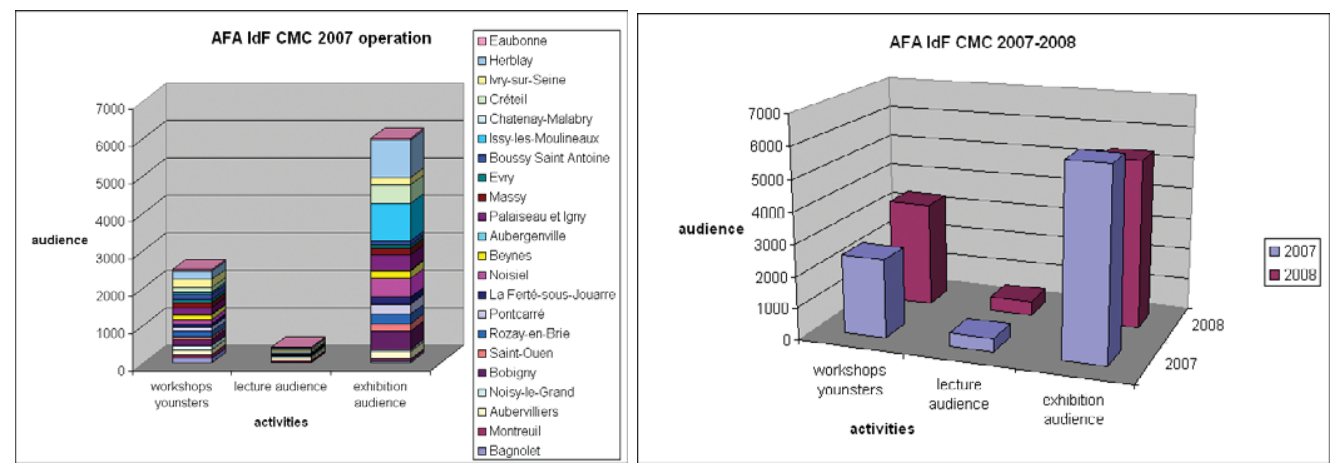

Figure 3. AFA IdF CMC events. (Left) Audience in 2007. (Right) Relative audiences in 2008 and 2007.

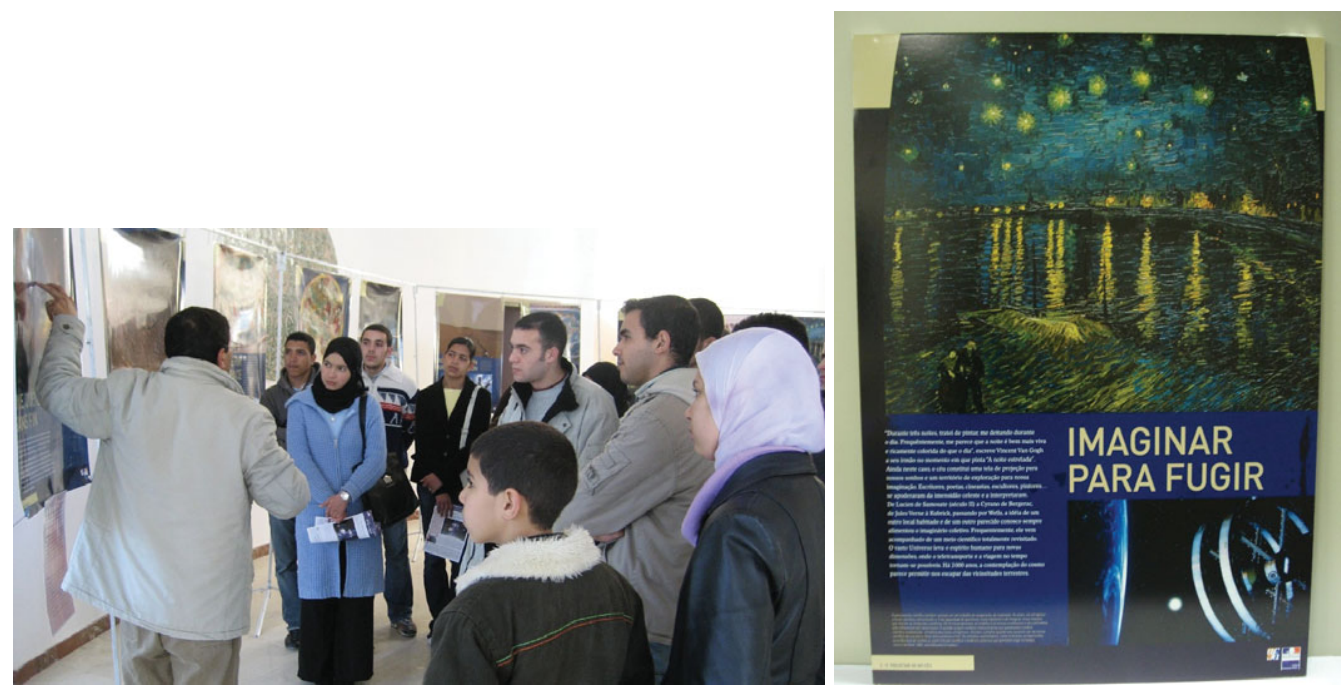

Figure 4. (Left): Presentation by IFO and FCO at the Université des Sciences of Oudja (Morocco). (c) ANAP. (Right): Translated copy of CMC touring in the framework of Brazil-France year. (c) Ministère des Affaires Etrangères.

During this operation, scientists or specialists in the history of astronomy also delivered 13 lectures and three 1- or 2-day training sessions were set up for activity organisers and leaders. A wide variety of workshops was offered in each location: Two or three days of scientific workshops, such as sky maps or sundials and sometimes water-rockets workshops; Art workshops such as science-fiction model building making use of daily life 
objects, digital pictures processing or science-fiction and tales writing. In 2008, the same kind of operation $\dagger$ was set up in the same Ile-de-France locations. As shown in Fig. 3 they were very similar in terms of audience. This second campaign confirmed a fact already observed during the first: the audience reached is more socially mixed in school and college events than in library events. CMC presentations abroad: As shown on Fig. 4, the Foreign affairs French ministry used CMC exhibition in transnational events in Maghreb, Middle East, Pakistan and Bielorussia as well as in Latin America, mainly in Brazil for the France-Brazil Year's celebrations in 2009. For those events, the texts were translated into Spanish, Portuguese, Russian and Arabic.

\section{Evaluation}

At the organisers' level, CMC has confirmed its relevance in allowing a wide range of social partners to set up astronomical events. Organisers feedback shows that CMC offered a ready to use and self-contained tool well-adapted to an unguided visit (relevant and easy to understand pictures and texts), and proved as well to be an efficient opportunity to aggregate complementary activities suggested by local partners as artistic, technical and scientific workshops.

At the visitors' level, as the authors decided not to set up a general impact survey, data is not available for all events. Qualitative elements, however, obtained from lecturers, demonstrators and other activity leaders interviewed by the authors suggests that the dialogues set up by the visit of CMC concerned more general topics about astronomy than specific cultural ethnical beliefs. This has been confirmed for directly AFA-organised operations (e.g. IdF CMC) by elements collected during the authors' dialogue with the public at the end of the lectures or guided visits. They noticed a great wish for dialogue about cosmology and life in the universe, but less interest about comparative ethnology, excepting some general religious matters (but for which people would usually not refer explicitly to their own beliefs).

\section{References}

De Guignes, C.L.J. 1782, Planisphr̀e céleste chinois, avec le catalogue des étoiles et la suite de toutes les comt̀es observées à la Chine, depuis l'an 613 avant J.-C. jusqu'à l'an 1222 de l'ère chrétienne (Paris: De Moutard)

Knobel, E.B. 1917, Ulugh Beg's Catalogue of Stars, Revised from all Persian Manuscripts Existing in Great Britain, with a Vocabulary of Persian and Arabic Words (Washington, D.C.: The Carnegie Institution)

Las Vergnas, O. et al. 2005, Ciel, Miroir des Cultures, a 14 posters exhibition (Paris: Association Française d'Astronomie) $\ddagger$

$\dagger$ The main difference was that a new poster exhibition just published by AFA was proposed to complete CMC Reflets de ciel : rêves et raisons (i.e. Heavens reflexions: dreams and raisons). $\ddagger$ see http://www.afanet.fr/CMC/Default.aspx 